\title{
Urdimento
}

\section{CORPO, CORPUS E CORPA: DA VIOLÊNCIA DE GOODY, DE VINEGAR TOM}

\author{
Fátima Costa de Lima ${ }^{1}$
}

\section{Resumo}

Reflexões de uma atriz sobre a interpretação de Goody, personagem da montagem teatral de Vinegar Tom, encenada pelos formandos da Universidade do Estado de Santa Catarina no ano de 2008, sob a direção de Maria Brígida de Miranda. Goody tortura mulheres, seu ofício na Inquisição inglesa do século XVII. Os corpos torturados tornam-se, neste artigo, espelhos que revelam a violência de Goody contra seu próprio corpo de caçadora de bruxas.

Palavras-chave: personagem, corpo, atriz.

\begin{abstract}
This paper consists of an actress' reflections on playing Goody, a character in the play Vinegar Tom, staged by the graduating class of 2008 at the University of the State of Santa Catarina and directed by Maria Brígida de Miranda. During the seventeenth century English Inquisition, Goody works torturing women. In this paper, the tortured bodies are seen as mirrors which reflect Goody's violence against her own witch hunter's body.
\end{abstract}

Keywords: character, body, actress.

Uma mulher de idade avançada cuja profissão é praticar violência contra outras mulheres. Seu trabalho, além de normalizado e legal, é altamente estimado e estimulado numa época histórica em que o diabo assombra o corpo feminino e deve fazê-lo para que a instituição mais poderosa do Ocidente tenha como justificar tal poder. Esta mulher, certamente abençoada pela Igreja e seu Deus, é Goody, a assistente de outro personagem, um bemsucedido caçador de bruxas do Barroco inglês. Criação moderna de uma personagem clássica, a vilã barroca tem uma curta e forte aparição no final do texto dramatúrgico Vinegar Tom, criação original de Caryl Churchill com o grupo Monstrous Regiment. Como explica Cláudia Mussi (que também traduziu o texto para a montagem catarinense), a "primeira montagem de Vinegar Tom no Brasil, com tradução inédita, aconteceu na Universidade do Estado de Santa Catarina (UDESC) nas disciplinas obrigatórias Montagem I e Montagem II (2007.2/2008.1) sob a direção da professora Dra ${ }^{a}$ Maria Brígida de Miranda" (MUSSI, 2008, p.1). O espetáculo foi encenado pela turma de

'Professora do Departamento de Artes Cênicas da UDESC. Doutoranda do Programa de Pós-Graduação da História-CFH-UFSC. Atriz e cenógrafa. 


\section{Urdimento}

formandos do Departamento de Artes Cênicas. Eu, autora do presente artigo, fui convidada para substituir a atriz titular da personagem Goody, Mariana Cândido, em algumas sessões de teatro. É, então, como atriz e pesquisadora que me apresento neste pequeno texto.

Goody é uma personalização do paradoxo barroco. Representante do Bem Oficial, diminutiva, "boazinha", ela encarna a fonte dos medos de todas as mulheres de que se aproxima. À primeira vista, é uma personagem objetiva e plana, quase estereotipada, em sua extrema certeza da função de assistente do inquisidor. Juntos, ela e Packer chegam a uma pequena vila para, com métodos eficazes, arrancar sob tortura a confissão de mulheres delatadas por suas próprias vizinhas. A peça, nas três quartas partes iniciais, desenvolve o enredo desta pequena cidade em que camponeses cruzam seus miseráveis cotidianos. As mulheres, de amigas cordiais ou vizinhas que se freqüentam, evoluem, por uma série de motivos aparentemente mesquinhos, a uma situação de delação em que algumas acusam outras de bruxaria e, por fim, acabam todos e todas na Praça Central à espera dos representantes da Inquisição. Obviamente, texto e espetáculo estão repletos de meandros dramáticos interessantes para a pesquisa teatral. Infelizmente, não poderei dedicar-me a eles, pois certamente não há tempo ou espaço para tal aprofundamento. Restringir-me-ei apenas ao final de texto e espetáculo, a partir do momento em que Goody e seu chefe surgem na cena.

Quando os dois chegam ao palco, a mudança cenográfica é evidente. Temos aí uma ruptura abrupta, típica da fragmentação que Walter Benjamin (2004) atribui aos dramas trágicos do Barroco alemão. O pequeno aglomerado de poucas famílias recebe, com excessivo respeito devido ao máximo temor, as duas autoridades que deverão sentenciar as mulheres acusadas. De recatados cômodos de casas e clareiras de florestas que preenchiam o lento tempo de pequena cidade, a cenografia, com a entrada da dupla inquisidora, é a primeira a se modificar. Torna-se a praça principal, as câmaras de tortura e o cadafalso final onde serão enforcadas as pecadoras. A ambientação cênica é no mínimo interessante, pois, ao optar por um não naturalismo ou realismo, aposta na imaginação de espectadoras e espectadores para materializar diferentes espaços dramatúrgicos.

Apesar de representantes do Terror, Goody e Packer não agem exatamente contra esta população: foram chamados pela cidade e, nas palavras de Goody para Alice, uma das mulheres penitenciadas, eles atuam "para sua próprio bem, sabe? Salvar você do diabo. Se deixarmos você ficar como está, será condenada para sempre e é melhor uma dorzinha agora do que uma eterna..." (CHURCHILL, 2008, p. 35). Goody é, por outro lado, extremamente consciente e orgulhosa de sua profissão. Segundo ela, 


\section{Urdimento}

$\mathrm{Na}$ Inglaterra, não temos meios [de tortura] tão minuciosos [quanto os de outros países], nossos meios são lentos, mas eles acham a verdade no fim, quando um homem bom e habilidoso como Henry Packer está investigando. Ele vale tudo o que the é pago, e eu ganho o mesmo, o que é muita bondade dele insistir nisso. (Idem)

Seu elogio ao chefe e evidente submissão não são mais do que uma estratégia para suportar sua própria crença na importância de suas ações. Ela segue, na continuidade de seu extenso monólogo, pregando as vantagens econômicas deste serviço:

Embora algumas pessoas digam: 'O que, o preço de uma vaca só para enforcar uma bruxa?' Mas eu lhes digo que pensem no prejuizo que uma bruxa traz às suas propriedades, como uma vaca morta hoje, um cavalo amanhã $\tilde{a}^{2}$ sem contar as cabras e ovelhas e galinhas. Por este preço você obtém a sua salvação, além de se ver livre de alguma doença ou até de uma morte inesperada. (Ibidem)

Mais do que uma ameaça, esta fala traduz a satisfação de Goody com o que faz, ao ponto de se permitir ser porta-voz de sua profissão ao público do teatro, a quem se dirige ao dizer esta fala, por opção da diretora do espetáculo. Mas, porque fala ao público do teatro? Quais são os possíveis sentidos da fala de uma inquisidora barroca ao público do século XXI? Porque uma personagem fictícia com cerca de quatrocentos anos de idade pode dirigir-se a espectadoras e espectadores de hoje? Como uma mulher como Goody ainda pode sobreviver, mesmo que no teatro, e gerar sentidos quando se pavoneia de ser uma eficiente torturadora de mulheres para uma platéia muda que a assiste?

De Benjamin, sua pesquisa sobre o Trauerspiel-drama de luto, drama trágico ou drama barroco - alemão constrói, para além da análise do objeto artístico, uma ponte, fruto de uma arquitetura anamórfica, entre o barroco e o moderno. Contudo, a deformação, o excesso e a extravagância tão evidentes na personagem Goody talvez forneçam pistas para explorar vestígios de seu corpo em corpos femininos atuais. Devo esclarecer, antes de prosseguir, que não possuo competência ou intenção de explorar aqui um viés sociológico ou mesmo humanístico do corpo. O corpo desta mulher barroca escrita na década de 70 será confrontado brevemente com a fragilidade de outro corpo feminino, tanto quanto ele pode autoperceber-se nesta pesquisadora-atriz.

É quase uma dissecação de cadáveres, bem ao gosto dos artistas e cientistas barrocos, o trabalho de retirar a lápide para exumar os ossos ou suas cinzas e colocá-los, como numa espécie de aula de anatomia comparada, juntos: um corpo historicamente morto e cenicamente vivo, o de Goody. Outro
${ }^{2}$ Deve-se notar aqui que esta fala se reproduz aqui um pouco modificada em relação à tradução de Mussi, para dar voz à atriz tanto quanto à personagem. $\mathrm{Na}$ tradução original, se lê "como as vacas mortas, um cavalo", bem como "porcos e ovelhas e galinhas". 


\section{Urdimento}

corpo, historicamente vivo, mas que precisou, de certo modo, morrer para deixar viver Goody, este é o corpo da atriz. Imaginemos, por um momento, dois cadáveres-fantasmas estirados sobre uma mesma e grande maca numa pequena e abafada sala de um IML qualquer, entregues às operações postmortem das ruínas dramatúrgicas de uma mulher segura e violenta e de outra mulher, insegura e quase desesperada na batalha que travou contra si mesma para promover a aparição de sua personagem.

Este artigo torna-se então, ao mesmo tempo, cenotáfio e tumba. Cenotáfio, porque é a cova de um corpo que ainda não está ali, o corpo vivo da atriz. Tumba, porque Goody, assim como todas as mulheres do barroco, já não é mais do que esqueleto ou cinzas, vive apenas em nossa arte. Mais especificamente, a breve especulação sobre os corpos da personagem e da atriz talvez possam esclarecer um ao outro. O corpo de Goody pode ser mais do que uma mera máquina de torturar? Foi esta exatamente a agenda oculta da atriz em relação à personagem. A leitura alegórica da arte que propõe Benjamin sobre a dramaturgia barroca alemã fundamenta, neste viés, uma possibilidade da convivência de opostos - não o lugar do Belo, como sustentam as artes renascentista e romântica - numa mesma obra, no meu entender plenamente adequada a esta personagem cuja constituição advém, justamente, de seu íntimo distanciamento daquilo que ela é, uma mulher.

A teórica francesa de arte Christine Buci-Glucksman (2002, pp. 7577), postula traços comuns entre a alegoria moderna e a barroca. Em primeiro lugar, a alegoria apresenta uma intenção destrutiva do real, desnuda-o e fragmenta-o, fazendo com que apareça em forma de ruínas. O que o corpo explícito da personagem Goody faz aparecer ao ser tratado como alegoria do corpo feminino? O que resta de seu andar seguro e sua voz de arauto da Inquisição após sua destruição alegórica? $\mathrm{O}$ que ela não mostra às mulheres amarradas que ela sacrifica com seus instrumentos de tortura? Se, como segue Buci-Glucksman, a alegoria, na arte, leva ao limite ótico da obra, aquele que permite ler entre o visível e o invisível, o que desta leitura decorre são ambivalências. Quais são as ambivalências de Goody? Quais as incertezas incrustadas na rigidez de seu corpo se, por uma análise crítica, fosse amarrado e perfurado à sua própria maniera de grande profissional da Inquisição? $\mathrm{Na}$ esteira de Benjamin, Buci-Glucksman afirma que as obras alegóricas barroca e moderna conduzem, ambas, a uma versão catastrófica e imaginária da história. Goody protagoniza, em Vinegar Tom, a catástrofe contra-reformista do século XVII. Mas, segundo Buci-Glucksman, a obra expressará aquilo que ela denomina como dois sentimentos. Um deles é do Trauer, do luto, sua dor e aflição. O outro, do Spiel, seu caráter transitório, seu movimento, sua passagem, seu jogo, seu teatro. Somente nestas condições a obra revela sua verdade. Assim, o corpo martirizado do tirano barroco do Trauerspiel de Benjamin atualiza-se 
no corpo feminino moderno de Buci-Glucksman, para quem "a mulher não é somente a alegoria da modernidade. Ela é também o protesto heróico contra esta modernidade das grandes utopias antropológicas". (Idem)

Podemos ver Goody como uma figura destas "grandes utopias antropológicas"? Penso que sim, quando ela mesma declara que "Assim [sendo uma torturadora] eu me mantenho saudável mantendo este grande país saudável”? (CHURCHILL, 2008, p. 35) Não é ela quem comenta com seu chefe, o caçador de bruxas Henry Packer, que "Nós merecemos nosso salário"? (Idem) Não é ela quem desafia as maldições da velha suposta bruxa Joan Noakes em sua última fala sob tortura, imediatamente antes que a torturadora a arraste para seu enforcamento: "Quem acreditaria nisso [em você]?” (Ibidem, p. 39) Goody certamente faz parte dessa imensa antropologia do Ocidente que submeteu os corpos, no barroco, ao ferro e ao fogo, e hoje os submete à vigilância internalizada e generalizada de que fala Foucault (1999), panoptismo que nos libera das Goodys que nos vigiariam do lado de fora porque elas já vivem dentro de nós. Contudo, será possível perceber a Goody, invisível, fora de nós?

Goody é a personagem que menos tempo permanece nas cenas de Vinegar Tom. Sobe por primeira vez ao palco no final do espetáculo e pouco fica, pouco fala. Entretanto, a autora lhe reservou o maior texto corrido deste texto teatral. Ademais, é uma das raras vezes em que uma personagem, neste espetáculo, dirige-se, solitária e sem contracena com o elenco, apenas ao público. Em sua fala, sozinha, paradoxalmente estabelece o diálogo a platéia atônita. Neste momento, ela enuncia as virtudes de sua profissão de caçadora de bruxas. Algumas falas já foram aqui anteriormente citadas. Agora vou me deter sobre uma outra que me incomodava como um zumbido insistente no ouvido enquanto trabalhava na criação da personagem. No final de seu "bife", Goody defende seu ofício com os seguintes termos: "Melhor que ficar em casa sendo uma viúva. Eu terminaria como uma mulher velha, você vê, leve da cabeça e cheia de ódio com seus feitiços e poções". (CHURCHILL, loc.cit., p. 35) Eis as questões que, para mim, ainda ecoam: o que teme Goody? De que essa poderosa mulher tem medo? Qual imagem ela possui, daquilo que teme?

Referindo-se à sua outra possibilidade de vida, eu diria que Goody, em primeiro lugar, refere-se a seu próprio corpo: o corpo desta mulher, se não fosse uma caçadora de bruxas seria, simplesmente, o corpo da própria bruxa. Em sua própria imaginação, só há duas opções: ser torturadora ou torturada. Além de bruxa, uma mulher sem homem, porque "viúva". Ora, é interessante reparar como, no texto, a condição de viúva é reservada à bruxa maior, delatada por suas vizinhas, em oposição à Margery, delatora, a única 


\section{Urdimento}

${ }^{3} 0$ Malleus Maleficarum (traduzido para português como Martelo das Feiticeiras ou Martelo das Bruxas) é um livro escrito em 1484 e publicado em 1486 (ou 1487), por dois monges alemães dominicanos, Heinrich Kramer e James Sprenger. Tornou-se uma espécie de "manual contra a bruxaria", amplamente utilizado pelos inquisidores para identificar bruxas e os malefícios causados por elas, além de conter procedimentos legais para torturá-las a sim de acusá-las e condenálas." Disponível em: http://www. spectrumgothic.com. br/ocultismo/livros/ malleus.htm casada dentre elas. Seu homem, Jack, é não somente um dos pivôs da delação, como também assegura, junto com a mulher, que se chegue à situação trágica final, da tortura e do enforcamento.

Além de tornar-se bruxa e sozinha, Goody teme também o destino da mulher "leve da cabeça". Sua estranha racionalidade apaga em sua mente os vestígios da própria demência. Ou alguém imagina que uma mulher possa tranquila e profissionalmente torturar outra a não ser que tenha, para isso, sacrificado sua própria lucidez? O que, entretanto, autoriza Goody a esta perversa compreensão da loucura? A própria sociedade barroca com suas rigorosas regras eclesiásticas aderidas a uma configuração de Estado autoritário e especialmente cruel com os corpos das mulheres. Em suas desrazão feminina - e perversa razão barroca - Goody é, enfim, extremamente coerente com o mundo em que vive.

Por último, investigo: de que sentimento ela se livrou? Do ódio. O ódio, em sua fala, se cola às "poções" das bruxas barrocas. Este ódio vedaria a Goody ser a cuidadosa profissional que ela é. Esta energia de fundo sentimental e limítrofe faria com que a personagem perdesse a postura corporal da torturadora. Portanto, Goody é uma mulher sem ódio. Tortura seguindo regras, os preceitos dispostos em manuais como o Malleus Malleficarum ${ }^{3}$ que, na cena, é atualizado em duas alegorias modernas dos personagens históricos Kramer e Sprenger: através de uma leitura brechtiana, eles se tornam personagens masculinos modernamente caracterizados por atores homens.

Quanto à imagem que Goody faz dela mesma nestas duas linhas de fala é interessante como, ao dizer este pequeno texto, o corpo da atriz se arcava, já nos ensaios, quase que instantaneamente na direção das palavras que pronunciava. O poder da linguagem conduzia seu corpo ao de uma mulher que nem de longe preserva a postura ereta dez Goody. Neste pequeno intvalo em que descreve a mulher que ela não quer ser, a atriz perdia a firmeza das mãos necessárias ao corte da carne sem prejudicar as partes, o que levaria a torturada a uma morte precoce, antes que ela confessasse seus pecados. A atriz abandonava a coluna firme daquela que tranquilamente, em meio a uma sessão de tortura, descrevia às torturadas como havia encontrado sinais - um caroço, uma mancha ou um terceiro seio - no corpo de outras vítimas; ou quando elas confessavam suas relações com o demônio, este corpo estranho.

Jean-Luc Nancy (2006) especula sobre a experiência de ter recebido, em seu próprio corpo, um coração transplantado. Discorre sobre um corpo estranho ao corpo humano que, por esta operação invasiva, se torna intruso a si mesmo. Falando da condição do humano, ele não leva em conta 
especificamente a condição feminina de carregar outro corpo. Uma estranha miopia masculina faz com que o autor não consiga pensar no que é estranhado e entranhado em nosso corpo desde que a linguagem nos nomeou mulheres, em oposição ao que é adâmico. Quando fala de corpus em outro texto seu, Nancy (2000) supõe corpos contemporâneos que, profundamente imagéticos, lograram ultrapassar sua condição de res extensa, de meros ocupantes dos espaços que nunca foram seus. Agora,

aquilo que vem é o que nos mostram as imagens. Os nossos milhões de imagens mostram-nos milhões de corpos - como jamais eles forma mostrados. Multidões, acumulações, tumultos, montões, filas, ajuntamentos, pululamentos, exércitos, procissões, colisões, massacres, carnificinas, comunhões, dispersões, um excesso, um transbordar de corpos sempre em massas compactas, sempre reunidos (nas ruas, em conjuntos, megalópolis, periferias, lugares de trânsito, de vigilância, de comércio, de tratamento, de esquecimento) e sempre abandonados a uma confusão estocástica dos mesmos lugares, à agitação, que os estrutura, de uma incessante partida generalizada. (NANCY, 2000, pp. 39-40)

Embora avançando na sua relação com o cenário, o mundus corpus, Nancy insiste, e com ele nós, em tratar todos os corpos como humanos e genéricos. Talvez seja mais instigante pensar, com Mario Perniola (2005), em muitos corpos, com muitos sexos, a fim de reconhecer alguma especificidade no corpo feminino: no outro sexo, pensar inéditos gêneros e sexualidades. Escrevendo, seguimos falamos de corpo, no masculino. E quanto a nossos corpos de mulheres, quando fazemos nosso teatro?

Gostaria, neste final, de abandonar um pouco Goody e Vinegar Tom para discutir a última questão à luz de um episódio recente que vivi numa oficina do encontro Vértice Brasil ocorrido em julho de 2008, em Florianópolis. Mulheres do teatro local, nacional e mundial se encontraram em uma semana de intensa programação com oficinas, pequenas apresentações, palestras, ceias coletivas etc. Dentre os muitos eventos, tive a oportunidade de participar da oficina A Presença da Performer Feminina, ministrada por Jill Greenhalgh, fundadora do Projeto Magdalena - Rede Internacional de Mulheres no Teatro Contemporâneo. Nesta oficina estivemos, cerca de vinte mulheres, por horas praticando "exercícios físicos, moldando a energia", como consta da página oficial do evento. Tais exercícios físicos consistiam em, num círculo, jogarmos bastões umas para as outras. A ministrante exigia que tais bastões fossem atirados "retos". Aos seus comandos, em espanhol, de "Palo reto!" e "Palo duro!", aquelas mulheres se esforçavam por 


\section{Urdimento}

${ }^{4}$ Estou utilizando aqui noções da linguagem lacaniana sobre conceitos e operações daquilo que é inconsciente. Para maiores esclarecimentos, sugiro a leitura de LACAN (1998) e HARARI (1990). atingir o nível de excelência do exercício. Num dado momento Greenghalg, exemplificando a base corporal que fundamentava aquela prática, solicitou que respondêssemos com o corpo a uma palavra que ela pronunciaria. Foi interessante observar os vinte corpos respondendo quase exatamente igual e de improviso (sic), à palavra "samurai".

No final desta manhã, a ministrante incluía numa roda as participantes que ela escolhia, uma a uma. Quatro atrizes não foram chamadas. Eu era uma delas. Por algumas destas "reais" armadilhas "daquilo que é inconsciente", porém, entendo que não conseguiria livrar-me o meu "eu" o suficiente como para observar a "causa" de minha própria "falta" naquele exercício final". Mas pude perceber que outra atriz, também excluída, apresentava um corpo visivelmente despido da prontidão e da força de guerreiro que o exercício requisitava. Pensando sobre os treinamentos contemporâneos das atrizes, a questão que surge é se aquela mulher preparada para torturar outras mulheres ficou no barroco. Pergunto-me se os treinamentos das atrizes já não deveriam, nos dias de hoje, procurar aquilo que é do corpo feminino. Se o teatro não deveria colocar no palco corpos grávidos, corpos que amamentam, corpos com TPM, corpos femininos que são diferentes mesmo quando expostos ao seu mais banal cotidiano, ao invés de procurarmos os modelos masculinos de guerreiros samurais e seus "palos" retos e duros, no teatro. Perniola, em livro já citado neste texto, critica a cena libertária dos anos 60 que, segundo ele, se tornou conservadora em suas duas vertentes atuais: do teatro da santidade e do teatro atlético. Qual deles é o nosso? Que teatro estamos fazendo? Há outros teatros possíveis?

Creio que Goody pode contribuir com nossa reflexão de mulheres na cena de teatro. Em algum momento de sua fictícia vida, de sua curta duração nos palcos, ela se presta a imaginar e a informar ao público a mulher que ela não foi. As falas da personagem trilham, transportados na voz da atriz o "significado da palavra ser e dos indicadores de enunciação", a direção de uma gramática da linguagem que se conforma, segundo Agamben (2006), como "estrutura originária da negatividade". É esta a compreensão de linguagem que conduz à atitude dialética, ainda que fantasmática, de uma personagem que opera, embora não seja exatamente este seu desejo, e sim da atriz, a crítica do corpo feminino. Creio que tal procedimento exige, antes mesmo da reflexão de uma mulher sobre o que ela não se imagina sendo, o ato de ver-se, simplesmente, como mulher. Barrocamente, para o bem e para o mal. Se em algo disto se pode vislumbrar um vestígio de sentido, resta aqui a proposta de que nos dediquemos com mais carinho e cuidado ao exercício auto-reflexivo, necessariamente crítico, a fim de que possamos nos referir algum dia, quem sabe, à nossa própria corpa. 
Urdimento

\section{Referências bibliográficas}

AGAMBEN, Giorgio. A linguageme a morte. Um seminário sobre o lugar da negatividade. Tradução de Henrique Burigo. Belo Horizonte: Editora UFMG, 2006.

BENJAMIN, Walter. Origem do drama trágico alemão. Tradução de João Barrento. Lisboa: Assírio \& Alvim, 2004.

BUCI-GLUCKSMAN, Christine. La folie du voir. Une esthétique du virtuel. Paris: Galillée, 2002.

CHURCHILL, Caryl. Vinegar Tom. Tradução de Cláudia Mussi. Florianópolis, 2008 (não publicada).

FOUCAULT, Michel. Vigiar e punir. História da violência nas prisões. Petrópolis: Vozes, 1999.

HARARI, Roberto. Uma introdução aos quatro conceitosfundamentais de Lacan. Tradução de Marta M. Okamoto e Luiz Gonzaga B. Filho. São Paulo: Papirus, 1990.

LACAN, Jacques; texto estabelecido por MILLER, Jacques-Alain. $O$ Seminário. Livro 1 1: os quatro conceitos fundamentais da psicanálise. Rio de Janeiro: Jorge Zahar, 1998.

MUSSI, Cláudia. As estratégias brechtianas nas canções de Vinegar Tom. Blumenau: Anais da I Jornada Latino-americana de Estudos Teatrais, 2008.

NANCY, Jean-Luc. Corpus. Tradução de Tomás Maia. Lisboa: Passagens, 2000. . El intruso. Traducción de Margarita Martinez. Buenos Aires: Amarrortu, 2006.

PERNIOLA, Mario. O sex appeal do inorgânico. Tradução de Nilson Moulin. São Paulo: Studio Nobel, 2005.

SPRENGER, James e KRAMER, Heinrich. Malleus Malleficarum. El martillo de los brujos. Buenos Aires: Ediciones Orion, 1975. Disponível em: <http://www.spectrumgothic.com.br/ocultismo/livros/malleus.htm>. 